\title{
DA SOLIDÃO DO DESERTO AO \\ CAOS DAS TREVAS EXTERIORES: ASCESE E INVENÇÃO EM PAULO LEMINSKI
}

FROM THE SOLITUDE OF THE DESERT TO

THE CHAOS OF OUTER DARKNESS:

ASCESIS AND INVENTION IN PAULO LEMINSKI

Everton de Oliveira Moraes

Universidade Estadual do Paraná

Curitiba - Brasil

\begin{abstract}
Resumo
A partir de meados da década de 1970, o poeta Paulo Leminski escreve alguns ensaios manifestando sua preocupação com o problema do esgotamento dos "recursos naturais", a iminente catástrofe ambiental, a possível hecatombe nuclear, e com a consequente crise dos modos de vida dominantes no mundo moderno-ocidental. Leminski se dedica, sobretudo, a investigar o modo como a literatura participa desse momento histórico de escassez. Buscando pensar o lugar da arte nessa crise, ele recorre a uma série de personagens conceituais e históricos que, sob o signo da ascese, se contrapóem à cultura da afluência, ao ativismo e à teleologia progressista, que caracterizam a sociedade brasileira da década de 1970, e seu correlato artístico: as literaturas engajadas, tanto nas suas versôes experimentais como nas ideológicas. Esse artigo busca pensar que tipo de experiência do tempo está em jogo nessa ascese poética leminskiana.
\end{abstract}

Palavras-chave: Paulo Leminski, literatura, tempo, catástrofe ambiental.

\section{Abstract}

In the 1970s, poet Paulo Leminski wrote a few essays expressing his concern about the depletion of natural resources, the imminent environmental catastrophe, the possible nuclear hecatomb and the crisis of the dominant ways of life in the modern Western world. Leminski was interested in investigating how literature participated in this historical moment of scarcity. Seeking to ascertain the role of art in this crisis, he used a series of conceptual and historical characters that, in the name of ascesis, fight against

\section{Resumen}

A partir de mediados de la década de 1970, el poeta Paulo Leminski escribe algunos ensayos manifestando su preocupación por el problema del agotamiento de los "recursos naturales", la inminente catástrofe ambiental, la posible hecatombe nuclear y la consiguiente crisis de los modos de vida dominantes em el mundo moderno-occidental. Leminski se dedica, ante todo, a investigar el modo en que la literatura participa en ese momento histórico de escasez. Al pensar el lugar del arte en esta crisis, recurre a una serie de 
the culture of affluence, activism and progressist teleology that characterized Brazilian society in the 1970 s and their artistic correlates: both in their experimental and ideological versions. This article seeks to surmise what kind of experience of time is involved in Leminski's poetic asceticism.

Keywords: Paulo Leminski, literature, time, environmental catastrophe. personajes conceptuales e históricos que, bajo el signo de la ascesis, se contraponen a la cultura de la afluencia, al activismo y a la teleología progresista, que caracterizan la sociedad brasileña de la década de 1970 y su correlato artístico: las literaturas políticamente compromisadas, tanto en sus versiones experimentales como en las ideológicas. Este artículo busca pensar qué tipo de experiencia del tiempo está en juego en esa ascesis poética de Leminski.

Palabras claves: Paulo Leminski, literatura, tempo, catástrofe ambiental.

\section{Ascese e escassez}

Em 1977, Paulo Leminski publica no caderno Anexo ${ }^{1}$, suplemento cultural do jornal Diário do Paraná, um ensaio chamado "Ascese e escassez" (LEMINSKI, 1977a: 5), que faz parte do imenso repertório de escritos que o poeta publicou em periódicos ${ }^{2}$, parcialmente reeditados nas coletâneas Ensaios e anseios crípticos (vol. 1 e 2). No texto, Leminski se questiona, na esteira dos desdobramentos do relatório do Clube de Roma ${ }^{3}$ e da intensa mobilização ecológica que a ele se seguiu, a respeito das exigências que o "esgotamento dos recursos naturais" e a catástrofe ambiental em curso fazem aos modernos. Pergunta-se, por exemplo, sobre quem mais sofreria com a escassez e quem estaria mais preparado para a situação histórica em que a palavra "economia" deixaria de significar "gestão eficaz dos recursos" para adquirir o status de "poupança" urgente daquilo que havia restado dos elementos fundamentais à manutençáo da vida humana (LEMINSKI, 1977a: 5).

A finitude dos "recursos naturais", de acordo com Leminski, colocaria um limite à teleologia progressista da modernidade, bem como aos modos de existência que corresponderiam a ela. A realização da utopia desenvolvimentista, segundo a qual, no futuro todos os seres humanos poderiam desfrutar dos benefícios do desenvolvimento e do progresso, estaria comprometida:

1 Trata-se de um suplemento criado por iniciativa do poeta e jornalista Reynaldo Jardim e no qual Paulo Leminski era editor de texto e responsável, em grande medida, pela proposta editorial.

2 Além do Diário do Paraná, publicou também diversos ensaios e poemas na Folha de São Paulo e no Correio de Notícias, além de jornais alternativos como Pólo Cultural e Raposa.

3 Documento composto por cientistas, industriais e políticos, destinado a apontar os efeitos devastadores da ação do ser humano sobre o meio ambiente global, propondo limites para o crescimento econômico. 
Nunca o desenvolvimento tecnológico (quantitativo, progressivo, inexorável, tomado como um Absoluto Onipotente) vai poder estender a todos os homens de todas as raças aquele nível de vida hollywoodiana (carros na garagem, um aposento para cada filho, geladeira cheia): os recursos naturais vão acabar bem antes (LEMINSKI, 1977a: 5).

Essa utopia progressista teria algumas de suas imagens mais bem acabadas no cinema hollywoodiano da época, nos filmes em que figuravam famílias estruturadas, com seus jardins bem plantados, farto entretenimento, em um cotidiano tranquilo, só eventualmente interrompido por problemas vindos de "fora". Para Leminski, essa teleologia jamais se completaria, já que a racionalidade progressista esgotaria a "natureza" e suas "matérias-primas" bem antes disso. Por isso, na visão leminskiana é preciso aprender a viver com menos:

Exaustos os recursos, irremediavelmente abalado o equilíbrio do meio ambiente, vamos todos ter que nos contentar com menos. Menos coisas. Menos títulos. Menos.

Quando o grande Abalo Sísmico vier, os primeiros a senti-lo serão exatamente aqueles cuja desmesurada ambição de fartura excessiva provocaram o Grande Abalo. Não é a indústria automobilística o principal responsável pelo emporcalhamento das águas e dos ares deste planeta?

Os que sempre se contentaram com menos, com pouco, ou até com nada (em termos de possuir coisas), sofreráo menos. Nessa hora, quanto menos você possuir coisas, mais estará imune ao Abalo (LEMINSKI, 1977a: 5).

O que hoje se convencionou chamar de "catástrofe ambiental”, e que Leminski nomeia "Grande Abalo", atingiria em maior grau aqueles cujos modos de vida estariam mais fundamentados na afluência e na apropriação virtualmente ilimitada do planeta, na ação contínua sobre o mundo. Para o poeta, portanto, impóe-se a urgência de pensar em modos de vida que renunciem à abundância, à grandiloquência e ao desejo, tipicamente moderno, de "fazer algo", de se manter ativo, não ficar parado. A este desejo, que aqui nomeio "ativismo", Leminski opóe a figura do asceta como um exemplo de uma forma de vida mais adequada ao tempo que vem:

Um eremita das vastidóes da Tebaida, um dos chamados Padres do Deserto, era alimentado miraculosamente por um corvo, que lhe trazia, todo dia, uma maçã no bico. Perto da gruta do monge, corria um riacho onde ele jogava a casca da maçã trazida pelo corvo. Assim foi por muitos anos. Um belo dia, o monge achou que tinha atingido o cúmulo da santidade e partiu do lugar. Descendo ao longo do riacho, encontrou outra gruta, habitada por um monge da sua idade. 
Na conversação sobre as coisas do céu, o primeiro monge mencionou, com uma ponta de orgulho, a graça singular com que o Senhor reconhecera sua perfeição: durante 70 anos, um corvo lhe trouxera, todo dia, uma maçá.

O outro monge disse que, em matéria de favores divinos, não ficava atrás: ele se alimentara, por 70 anos, de uma casca de maçã que, miraculosamente, vinha boiando no riacho, todos os dias.

Temos sido o primeiro monge. Vamos, logo, ter que ser o segundo. (LEMINSKI, 1977a: 5)

O personagem conceitual que o poeta evoca como "representante" de um modo de vida outro, mais preparado para a existência pós-catastrófica, é o "asceta", uma figura historicamente marcada tanto pela renúncia de si como pela tentativa de, colocando-se como "fim de sua própria existência", criar um "equipamento de defesa" contra as adversidades da vida (FOUCAULT, 2006: 400). A ascese deve ser aqui entendida, nesse sentido, enquanto conjunto de práticas e técnicas rigorosas de relação consigo mesmo, através das quais o sujeito visa à sua própria transformação, seja ela espiritual ou corporal (FOUCAULT, 1998: 83). Nos ensaios leminskianos, este personagem aparece recorrentemente (com diversas variantes), sempre pautado por uma tentativa de fazer muito com pouco, experimentar o máximo de intensidade com o mínimo de matéria, criar "força estética" (LEMINSKI, 1997: 83) e existencial a partir do "quase nada", como na anedota dos monges e da maçã. Desse modo, é possível afirmar que, mais do que se contentar com o pouco que resta, existiria, segundo Leminski, uma nova geração "preparando" seu equipamento “econômico-mitológico" para a adoção de uma estética da "escassez":

Concomitantemente, está ocorrendo uma mutação na espécie, a olhos vistos, invisível apenas aos menos avisados. Uma nova geração (pelo menos suas camadas mais inventivas e atuantes) desistiu de possuir, preparando a espécie para o impacto que o Abalo e o Colapso acarretaráo. Eles estáo preparando o equipamento psíquico-existencial, sócio-pedagógico e econômico-mitológico para o Grande Transe. Esta gente será o amortecedor entre os tempos passados da Pluto-Utopia e a Nova Era de Ascese. A Era de Aquário, meu camarada, não será festival, não (LEMINSKI, 1977a: 5).

Ascese é o nome que Leminski, inspirado pelos monges cristãos (mas também pelos pensadores cínicos da antiguidade, hippies, xamãs, poetas de haikai, etc.), dá à nova condição a que todos estariam submetidos em um horizonte que se aproxima cada vez mais rapidamente. Para encará-lo, segundo ele, seria preciso inventar novas formas de viver, muito mais próximas da poesia do que da prosa: trabalhar a si mesmo para que se aprenda a viver com menos coisas, menos espaço, menos títulos, menos crescimento, tal como o "hippie de estrada” (LEMINSKI, 1977a: 5), ou ainda como a poesia ou o haikai, que 
exigem um intenso trabalho sobre suas formas para que funcionem dentro de uma métrica, de uma medida, de um modo de dizer. Seria fundamental, portanto, de acordo com o poeta, privilegiar a intensidade, a multiplicação das formas (de dizer e de viver), produzir a partir do mínimo, do "lixo". O que o poeta afirma, portanto, é algo análogo ao que diz Günther Anders quando reivindica a necessidade de ultrapassar a capacidade atual de imaginação do ser humano, para então imaginar a possibilidade de inexistência do "contexto" mesmo no qual se fala, diante de sua iminente destruição (ANDERS, 2013: 5) e, a partir disso, formular novas formas de existência.

\section{Literatura e escassez}

Apesar de seus inúmeros ensaios sobre a situação político-ecológica do mundo contemporâneo, é no campo das discussões literárias que Leminski mais investe na crítica do ativismo, questionando sua dimensão poética. Tal crítica se constitui como um afastamento dos modos de orientação temporal teleológicos que pautam grande parte do pensamento literário de seu momento histórico. Segundo o poeta curitibano, a literatura/poesia de seu tempo vive uma situação de esgotamento, em que já não haveria mais tempo para "gestos inaugurais" (LEMINSKI, 1993, p. 44), como teriam sido aqueles da poesia concreta, da Antropofagia, da Tropicália, nem para posturas emancipacionistas, como aquela da literatura social, que pretendia fazer da escrita uma forma de provocar transformaçóes na sociedade. Nesses tempos em que não haveria mais tempo, "as certezas se evaporam" (LEMINSKI, 1993: 44):

Aí está uma bela questão. A mais bela de todas para os que vivem do verbo. Quem escreve, vive hoje um ofício sem definiçôes. A literatura, mãe de todas as técnicas de escrever, morreu: foi atropelada por um trocadilho. A divisão da literatura em gêneros (poesia/prosa) está agora com seus limites borrados: já não se sabe, na prática do texto novo, o que é prosa, o que é poesia. Parece que a extensão de um texto define seu caráter de "prosa" e a brevidade seu caráter de "poesia". Mas não há mais certeza (LEMINSKI, 1975).

A partir da análise do conjunto de ensaios de Leminski que abordam esse tema, é possível pensar que aquilo que o poeta afirma ter morrido não é tanto a literatura em sentido amplo, mas o que ele chama de "discurso jorno-naturalista” (LEMINSKI, 2012: 102), uma forma de literatura que tinha no romance naturalista e no texto jornalístico suas expressóes mais características. Tais discursos seriam pautados por um desejo de "neutralidade", de objetividade na descrição da realidade e controle da imaginação poética, e encontrariam ressonância, por exemplo, no discurso acadêmico ou no discurso ativista/panfletário do escritor do social. É essa literatura que Leminski afirma 
ter encontrado seus limites históricos, e é ela que já não seria mais capaz de "castrar" a "fantasia" e o "mito" que a constituem secretamente, não se distinguindo mais da poesia e da ficção.

Ao aproximar a poesia/literatura da publicidade ou do design, os concretos já haviam abandonado a ideia de uma especificidade do "literário" enquanto dimensão distanciada da realidade (e por isso capaz de descrevêla com justeza), e devolvido a literatura a esta realidade, como participante ativa dela. A antiliteratura concreta, na visão de Leminski, desferia o golpe final na literatura jorno-naturalista. Não deveria surpreender, portanto, a transformação da prosa moderna, assim como dos recursos naturais, em mercadorias altamente valorizadas, já que elas constituiriam "bens inestimáveis da humanidade" (LEMINSKI, 1977a: 5) em processo acelerado de rarefação: "o texto tradicional está em crise, a despeito de sua relativa aceitaçáo como mercadoria (ou por isso mesmo). Poderia o texto ainda estar vivo e passando bem no interior do circuito elétrico?" (LEMINSKI, 1975).

Nesse cenário de incertezas, os escritores ativistas da literatura social buscariam reafirmar o caráter objetivo e comunicativo da literatura e fazer dela um instrumento da luta pelo progresso social e pela superaçấo do subdesenvolvimento do país. De acordo com Leminski, no entanto, a busca por superaçáo do atraso e do atavismo tomaria como instrumento uma forma não apenas em vias de extinção, mas também intimamente ligada ao exercício do poder da classe social que responsabiliza por este subdesenvolvimento, a burguesia. A luta pela "revolução" ou pela "transformação social" se constitui a partir de um desejo de retorno a uma linguagem que representaria a objetividade racionalista, a ordem e a estabilidade do mundo burguês (LEMINSKI, 201: 102).

Esses escritores sociais aos quais Leminski se refere faziam parte de uma esquerda artística que se poderia chamar, de maneira um pouco canhestra, de "esquerda ideológica". Se após o golpe militar, com a instalação da Ditadura, caía por terra a possibilidade de um pacto com a "burguesia" que, até certo ponto, havia incentivado e até financiado a chegada e a permanência dos militares no governo, esses intelectuais mantinham ainda no horizonte a ideia de superação de um atraso e da conquista da autonomia nacional, não apenas política e econômica, mas também capaz de dar conta da produção de uma consciência e de saberes próprios, adaptados ao contexto nacional. A arte, nesse pensamento, deveria estar a serviço de um "fim" (comunicação eficiente e didática com as "massas" alienadas), orientada, ao lado de outros saberes, na direção de um objetivo: a transformação social, nos seus mais diversos significados, da revolução ao reformismo progressista. Nessa concepção de arte e de escrita literária, o escritor teria, portanto, o papel de fornecer orientação temporal ao "povo subdesenvolvido". Tal modo de orientação temporal, 
insistentemente denunciado por Leminski como autoritário, poderia ser denominado "desenvolvimentismo".

Se a relação de Leminski com os escritores sociais é, via de regra, a do choque, a sua relação com os concretos é mais complexa. Afinal, o poeta foi, desde a juventude, muito próximo a Augusto e Haroldo de Campos e Décio Pignatari, chegando a se afirmar, algumas vezes, como continuador do projeto da poesia concreta e até como "mais concreto que os poetas concretos" (LEMINSKI, 1993: 36). Para a geração setentista, aliás, o concretismo não se configura como um movimento histórico do passado recente, mas como uma força atuante no seu presente. Tanto que conceitos como "invenção", "diluição", "novo", "informação são correntemente utilizados e ressignificados pelos jovens poetas experimentais da década de 1970, sem que maiores consideraçóes históricas e críticas sejam feitas. Leminski, que no começo dos anos 1960 havia aderido ao concretismo, vai aos poucos, a partir de sua experiência com os tropicalistas e com todo um conjunto de artistas que repensaram o significado de fazer arte no Brasil, questionando o pensamento concreto, especialmente o seu caráter prometeico e racionalista. No final dos anos 1970, quando escreve "Ascese e escassez", já acredita experimentar o "depois do concretismo", ainda que permaneçam, no seu discurso, alguns traços do ativismo que criticava nos concretos, como a afirmação da necessidade de "superar" certos modos de fazer poesia ou a significativa imagem da "central elétrica" (usada para descrever um modelo de produção artística inspirado em Maiakovski). Ao se referir à sua geração, Leminski afirma que ela havia priorizado o humor em detrimento do épico, e deixado de se preocupar com "planos-projetos-manifestos-plataforma [...] excludentes" (LEMINSKI, 1978b, $\mathrm{s} / \mathrm{p})$. Talvez tenha sido este um dos motivos pelos quais tenha publicado, em conjunto com Régis Bonvicino e Antônio Risério, o Plano Pirata, uma paródia do Plano Piloto da Poesia Concreta, no qual buscava, ainda que em tom de brincadeira, "afirmar os caminhos próprios" (LEMINSKI, 1977b, p. 3) de sua geração, tomando assim um distanciamento crítico em relação aos concretos.

Em carta a Régis Bonvicino, escrita em julho de 1977, Leminski dá uma pista de como entender seu desejo de fazer algo que estaria "depois do concretismo". Ali, o poeta afirma ser preciso "meter paixão em nossas constelaçôes", ainda que "sem abdicar dos rigores da linguagem" (LEMINSKI, 1993 , p. 37). Se os rigores vanguardistas dos concretos teriam permitido a Leminski e à sua geração escapar às tentaçôes autoritárias da "poesia de comunicação", eles funcionariam agora como lei, conjunto de limites que bloqueariam a multiplicidade dos possíveis. Em 1984, em uma visita a Brasília, tomada pelos poetas concretos como modelo de experimentação arquitetônica, Leminski escreve um poema sobre a cidade, que explicita algo do modo como o poeta se relaciona com seus "mestres": 
Em Brasília, admirei.

Não a niemeyer lei, a vida das pessoas

penetrando nos esquemas

como a tinta sangue

no mata-borrão,

crescendo o vermelho gente

entre pedra e pedra,

pela terra a dentro.

Em Brasília admirei.

$\mathrm{O}$ pequeno restaurante clandestino,

criminoso por estar

fora da quadra permitida.

Sim, Brasília.

Admirei o tempo

que já cobre de anos

tuas impecáveis matemáticas.

Adeus, Cidade.

O erro, claro, não a lei.

Muito me admirastes,

muito te admirei (LEMINSKI, 2013: 192).

A crítica de Leminski ao concretismo e ao pensamento desenvolvimentista expresso pela cidade náo se dá como ruptura ou recusa, uma vez que, para falar como o poeta, a produção poética de seu tempo o deglute e o pressupóe, mas fazendo uma experiência radical da poesia/cidade experimental. $\mathrm{O}$ desenvolvimentismo de Brasília e da poesia concreta não deveria, portanto, ser contraposto a um drop out ou ao retorno a um envolvimento original, mas subvertido por um "reenvolvimento cosmopolítico" (VIVEIROS DE CASTRO, 2011: 3) tramado a partir do erro, do clandestino, do crime que penetrava nos esquemas assépticos da cidade e a tornava viva, subdesenvolvida.

Leminski não explicitou a ligação de suas críticas à literatura social ativista e ao pensamento concreto com sua denúncia do modo de vida ocidental. No entanto, é possível imaginar que se trata, nos dois casos, de uma crítica dos limites do pensamento progressista e de seu desejo de aceleração, do tempo linear do gesto viril que pretende superar o passado e refundar a história. Assim como o modo de vida ocidental, que exaure os recursos naturais em nome de um desejo de abundância, os modos de produção literária desenvolvimentistas buscam sempre uma expansão sobre os múltiplos territórios da realidade, fazendo da literatura um modo de intervir na sociedade, seja de modo mais preciso, pontual e eficaz (concretos), seja de modo massivo 
e abrangente (escritores sociais). Mas se Leminski prescrevia a ascese como modo de vida capaz de lidar com a escassez de recursos naturais, qual seria o modo de composição poética que corresponderia a uma ascese literária?

Tradução e ascese

Em um artigo sobre a geração de poetas da década de 1970, Flora Sussekind descreve a tarefa literária de Leminski como a busca por uma ascese capaz de lhe conferir uma espécie de beatitude (SUSSEKIND, 2007: 45-75). Historicamente, a ascese esteve associada tanto à constituição de um modo de existência ligado à verdade, quanto à luta cristã contra as tentaçóes que atrapalhavam o trilhar do caminho da purificação. A ascese, no caso leminskiano, diz respeito à escrita de seus ensaios e poemas, bem como à constante problematização de si que ela implica. Ela poderia ser entendida como um exercício de crítica da atualidade, uma tentativa de, pelo exercício de tradução/comparação, perscrutar e eliminar as redundâncias poéticas e políticas que apenas reiteravam as formas dominantes de relação com o tempo (o desenvolvimentismo, em especial) e que permaneciam presentes em sua própria escrita.

Flora Sussekind afirma que a ascese, a provação e a purificação são elementos fundamentais da poética de Leminski, bem como de boa parte de sua geração. Segundo ela, diante da censura, da repressão, da violência e do quadro existencial e cultural que isso implica, tudo se passa "como se não fosse mesmo possível existir intelectualmente naquele momento sem, de algum modo, incorporar modelos hagiográficos" (SUSSEKIND, 2007: 51), sem uma certa simpatia pelas experiências corporais dolorosas e sua superação. Sussekind pretendeu chamar atenção para certa "ingenuidade" das interpretaçôes que enxergam os artistas dessa geração (ela se refere a Ana Cristina Cesar, Cacaso e Leminski) a partir da autoimagem formulada pelos próprios, tomando-os como heróis ou mártires em luta contra o seu tempo.

Se é verdade que essa geração, Leminski em especial, tem na ascese um tema e um procedimento poético recorrente e no sofrimento uma experiência fundamental de relação com o mundo, e se Sussekind tem razão ao vincular esses elementos ao contexto da Ditadura Militar, talvez se possa, no entanto, entender esse desejo de "beatitude" e essa produção de imagens da santidade em um outro sentido, isto é, menos como reação ao contexto violento e efeito colateral deste, e mais como a produção de uma outra forma de se relacionar com o tempo (CÁMARA, 2014: 184). Nesse sentido, talvez a ascese seja mesmo a figura que mais se adéque para descrever essa geração, não tanto pelo desejo de construção de uma autoimagem heroica, e sim pela constituição de 
outras formas de temporalização e subjetivação que implicam um incessante trabalho sobre si, uma constante tentativa de ir além (ou aquém) da "realidade objetiva" ou da "consciência histórica" por meio da arte.

O rigor artístico, o trabalho incessante sobre a forma, compreendido como elemento complementar à invenção e não como o seu oposto, é, também ele, um elemento central da ascese leminskiana. Assim, pode-se dizer que a habilidade de "obter o máximo com um mínimo de recursos", como já foi dito aqui, é um atributo do asceta. E se este último deseja, através de seus exercícios, inventar um corpo ou uma alma, o artista almeja a criação de "um novo objeto no mundo".

\section{Em busca do Rigor}

Iluminar o âmbito do conceito de invenção é relativamente fácil comparado com a tarefa de definir RIGOR. Em que consiste o rigor de um artista? Rigor é fidelidade a uma estrutura. É economia. É nāo-complacência. O contrário de "rigoroso" é arbitrário, sem necessidade, gratuito estruturalmente. Não essencial. Rigor é recusar o fácil, obter o máximo com um mínimo de recursos. Rigor é manter-se coerente ao projeto. E uma espécie de exatidão. Enquanto o conceito de invenção parece ter que ver com "informaçáo", o de rigor aparenta-se a redundância (a repetição, o já-sabido). Rigor é a manutenção de uma certa temperatura uniforme no conjunto da mensagem por mais nova que seja. A complementaridade dos dois conceitos revela-se no seguinte: nos grandes criadores, a distinção desaparece. É o inventivo rigor. "Há um mecanismo que parece ser modelo ideal para um sistema econômico: o da pilha atômica, da floresta e da vida: utilizar a eficientíssima mola que é uma retroação positiva, uma tendência que deseja sempre ir à frente, mas controlála negativamente" [Pierre de Latil] (LEMINSKI, 1977c: 2).

Esse rigor do artista-asceta, ao menos em seu modelo leminskiano, funciona a partir de um movimento de "equivocidade controlada" (VIVEIROS DE CASTRO, 2015: 87): "ir à frente", inventar, "explodir os códigos existentes", mas controlar o passo, modular a quantidade de inovação. $\mathrm{O}$ rigor, nesse sentido, funciona não apenas como controle de qualidade dos produtos artísticos, mas como modo pelo qual o sujeito suspende seus vícios e hábitos atuais e como método de limitar os excessos do Eu, de duvidar constantemente de sua orientação temporal. Se o asceta busca purificar seu corpo e sua alma, superando as tentaçóes, o artista faz da ascese a oportunidade de limpar sua linguagem dos excessos que marcaram, por exemplo, as geraçóes anteriores de artistas experimentais, com sua vontade de progresso.

A partir de alguns ensaios e poemas, dispersos entre os diversos momentos de sua produção, é possível identificar em Leminski um desejo 
de traçar uma genealogia dessas práticas rigorosas. No texto "Pajé", publicado apenas algumas semanas antes de "Ascese e escassez", o poeta chega a inserir esses personagens conceituais em uma espécie de "árvore genealógica" dos modos de vida baseados em algo próximo a uma ideia de "subsistência", na qual estariam incluídos os xamãs, os cínicos antigos, os taoístas, os beatniks, entre outros (LEMINSKI, 1977d: 6). Nesse mesmo texto, Leminski fala dos pajés/xamãs como sujeitos dedicados ao silêncio, à solidão, à contemplação, ao despojamento material, fazendo dessa renúncia à "Realidade Objetiva" um modo de produzir uma existência "puramente relacional", capaz de se relacionar com o cosmos e de ser afetada por ele de um modo completamente outro. Relacionando-se com animais, plantas e espíritos da floresta, meditando e acumulando saberes, o pajé atuaria como uma espécie de computador da tribo, mas também como seu cientista, poeta, psicólogo, analista de sistemas e filósofo, sendo fundamental para a subsistência dela, para seu futuro ${ }^{4}$.

A ascese e a solidão que Leminski identifica no pajé, no entanto, não são aquelas do sacerdote que prega o abandono do mundo em nome do ideal de um "outro mundo", essa figura tão denunciada por Nietzsche. $\mathrm{O}$ que interessa ao poeta é a ascese enquanto prática de exercícios rigorosos em busca da invenção de "mundos outros", que não estariam fora do "mundo atual", mas nos seus limites, em uma relação tensa com ele. O pajé/xamã é, desse modo, não apenas aquele que lhes fornecia o saber que garantiria sua subsistência em um contexto de crise e escassez, em que estavam perdendo seus mundos para a "Civilizaçáo", mas também o ser que propiciava à tribo o encontro com o Outro (outras espécies, outros pontos de vista, outras experiências, etc.). Enquanto mediador cósmico, o pajé atua "infundindo ânimo e alma àquelas musculaturas meramente eficazes", tirando os jovens de sua rotina de trabalhos e levando-os para os limiares da humanidade, onde se encontra com o "caos das trevas exteriores, infestadas de feras, demônios e outras entidades menos definidas" (LEMINSKI, 1977d: 6).

No caso do pajé/xamã, a descrição leminskiana pressupóe a ascese como um procedimento mais elaborado do que a mera rejeição da realidade cotidiana, como um afastamento do atual, do tempo produtivo da tribo, definido ironicamente por Leminski como "Realidade Objetiva", um mergulho no "mistério" e na "noite", no inatual, acolhendo o sofrimento decorrente do contato com uma realidade menos definida, com o mundo dos espíritos. Tal experiência exige do pajé um abandono de sua humanidade, o que o torna apto a se comunicar com outros seres e entidades. Após essa retirada do atual, o pajé retorna para a realidade cotidiana da tribo, mas para transformá-la, espantando ou atraindo a caça, frustrando a gravidez ou trazendo a fertilidade,

4 Leminski faz sua interpretação a partir da leitura de texto năo referenciado de Aryon Dall'Igna Rodrigues, linguista brasileiro, estudioso das línguas de uma série de povos indígenas. 
disseminando conhecimentos cosmológicos, poéticos e filosóficos extraídos das fronteiras do mundo humano.

A ascese aparece, portanto, como prática rigorosa de exercícios que visam ao apagamento e à diluição de si enquanto "eu" (dessubjetivação), esse sujeito do atual, tomada como condição sine qua non para a "invenção". Escrever poemas e ensaios, para Leminski, equivalia a colocar diante de si a sua "experiência bruta" (com outrem) e trabalhar para produzir uma forma a partir dela. Esses exercícios diziam respeito tanto à preparação "para entrar no espírito do poema" (LEMINSKI, 1989) quanto à própria escrita, pautada pela necessidade de recorrer ao menor desperdício possível de palavras.

\author{
Apagar-me \\ diluir-me \\ desmanchar-me \\ até que depois \\ de mim \\ de nós \\ de tudo \\ não reste mais \\ que o charme \\ (LEMINSKI, 2013: 84).
}

Ascetismo e xamanismo são nomes para aquilo que Leminski nomearia, em um texto de 1986, de paixão (LEMINSKI, 2009: 322-350). Uma ideia que, sob as mais diversas designaçôes, marcaria a produção poética de sua geração. Leminski define a paixão como uma espécie de sofrimento não ligado à ideia de dor, mas à condição de ser passivo de uma ação, de ser objeto de um afeto, de uma força (LEMINSKI, 1986: 325-326). A descrição leminskiana identifica essa passividade a algo como uma dessubjetivação, em tudo distinta da apatia. Segundo Leminski, o poeta é aquele que sofre, mais que todos os outros, a força da linguagem, sendo um "sofredor da língua", alguém que vive com dramaticidade as pressóes, achatamentos e imposiçôes dos signos, formas e estruturas linguísticas estabelecidas. Mas o poeta seria também aquele que sabe se manter em uma certa quietude, para melhor acolher os afetos (LEITE, 2012: 100-102) e que, no momento oportuno, "passa a devolver os golpes que tinha sofrido no início, no qual era uma vítima da língua, [...] a ser algoz, a torturá-la, a quebrá-la, passa prum outro momento de sua paixão" (LEMINSKI, 1986: 328), fazendo da poesia um instrumento de desatualização, de suspensão do atual.

Da mesma forma, o pajé sofreria o "caos das trevas exteriores" e, vivendo a experiência dessa paixão, confrontando-se com ela, torna-se capaz de dar um futuro à vida da tribo. Tal como aquele que sofre o sabisha, 
experiência (descrita pelos poetas japoneses de haikai) de abatimento e "interpenetração com todas as outras coisas" (LEMINSKI, 1998: 19), um "não fazer, [...] um fazer conforme a lógica interna do processo das coisas, é um conformar-se, [que] se assemelha aos processos da natureza, um deixarse ir, uma Abertura", ao contrário da "arte ocidental, que sempre colocou ênfase exagerada na 'expressão do eu" (LEMINSKI, 2012: 380). Tanto no caso do poeta como no do pajé, é só então, depois desse sofrimento, que a ação aparece, como resultado de um encontro com um outrem que afeta a si, e não como causa de uma transformação do mundo. Agir, na ascese leminskiana, não significa liberar explosivamente energias represadas pelos dispositivos sociais, tampouco calcular os movimentos com vistas à obtenção de determinados resultados na realidade, mas conformar os gestos para que eles não carreguem traços daquele ativismo que pretende agir pelos outros ou no lugar deles e impor o progresso/desenvolvimento como telos. Importa, para ele, criar uma consistência (inventar), mantendo um equilíbrio entre ação e paixão.

A aparição dos personagens conceituais da ascese nos ensaios de Leminski, no entanto, não se reduz à função de produzir modelos de subjetivação para um presente de escassez. Antes, eles estáo lá como figuras com as quais a escrita leminskiana se imbrica para constituir o texto como objeto/corpo relacional. É a própria relação com outros tempos e modos de existência que o texto busca reafirmar, inventando, desse modo, uma outra relação com o tempo. E faz isso por meio de outro procedimento, recorrente em sua produção: a tradução. Reivindicando um conceito de tradução que remete a Walter Benjamin e Haroldo de Campos, Leminski busca, em diversos ensaios e poemas, traduzir uma experiência do tempo (xamanismo ameríndio, sabisha, entre outras) para a sua atualidade, ou seja, submeter esta última ao choque com a primeira, confrontando modos de historicidade, iluminando outras formas de viver o tempo, alargando as possibilidades de experiência, tentando produzir uma imagem capaz de abrir o atual à multiplicidade temporal que nele existe.

Ao abordar o xamanismo, Leminski parece remeter a algo parecido com aquilo que anos mais tarde seria enunciado por Eduardo Viveiros de Castro, a saber, que "a verdadeira tradução da antropologia das sociedades de tradição não-ocidental para a antropologia das sociedades ocidentais deveria preservar certas relaçóes funcionais internas, e não apenas [...] continuidades temáticas e históricas" (VIVEIROS DE CASTRO, 2008: 45). A leitura antropológica que Leminski faz da figura do pajé/xamã náo o compara aos sacerdotes cristãos ou ao neo-xamanismo que ganha força no interior dos movimentos contraculturais da época, mas constrói uma analogia deste com o computador e o cientista/filósofo. Desse modo, a tradução que o poeta realiza, 
nesse e em outros ensaios, faz com que os conceitos do "outro" "deformem e subvertam o dispositivo conceitual do tradutor" (VIVEIROS DE CASTRO, 2015: 87) ou, para falar como Leminski, seu "aparelho econômico-mitológico" (LEMINSKI, 1977a: 5). O mito passa a ser tratado, por meio dessa tradução, não mais como a ilusão e erro conceitual do outro, mas como aquilo que, sendo consubstancial ao pensamento humano, pensa em nós. Um "nós" que diz respeito tanto aos modernos quanto aos extramodernos. Trata-se náo apenas de colocar modernos e selvagens em simetria, nem somente de explicar o outro por meio de uma linguagem familiar ao tradutor, mas de contestar os significados de palavras como "computador", "químico", "filósofo" e, sobretudo, "Eu", na língua de destino da tradução. Se essas palavras estavam, até então, intimamente ligadas ao logos, em oposição ao mito, importa, para Leminski, restituir a dimensão mítica dessas invenções modernas. E se o pensamento moderno se coloca como ponto necessário de chegada de um longo processo de desenvolvimento, é através da inatualidade do mito ameríndio que Leminski contesta essa teleologia. $\mathrm{O}$ poeta assume-se como afetado pelo Eu singular do xamá, esse sujeito que se retira do cotidiano da tribo buscando tornar-se um "ser puramente relacional".

A tradução, desse modo, mobiliza procedimentos literários que, mais do que chamar atenção para a exemplaridade daquilo que é traduzido, desatualizam a literatura leminskiana e a fazem incorporar a relação de paixão/ possessão. Desse modo, o pajé/xamá, o hippie, o padre asceta, o samurai, o poeta, entre outros, são figuras da alteridade evocadas náo tanto para fornecer modelos de vida aos contemporâneos, mas para fazer a poesia sair de seu atual, suscitar a invenção de outras formas de relação com o tempo.

Mas, para além disso, Leminski pensava o papel do pajé na tribo como algo análogo também ao papel do poeta no mundo moderno. Ambos estariam próximos por compartilhar uma vida mais contemplativa do que prática, em uma relação de suspensão com o atual que resultava em um "supra-cúmulo do pensar" e do imaginar. Mas também no gosto do poeta pela síntese, no esforço para evitar palavras desnecessárias, na busca por um certo "tom", em que estava em jogo conquistar uma linguagem "pam-pam", de "carne e osso" (LEMINSKI, 1989), que se coloca diante do leitor como um quase-corpo, um efeito de presença, e não como uma argumentação racionalista e verborrágica, com um sentido e uma orientação. Não se trata, entretanto, de um gesto inaugural, uma nova poética, mas do resultado de um procedimento poético ascético que abandona o ativismo moderno, em nome de um modo de vida que estaria à altura desses tempos de escassez, algo que Leminski esboçou chamar de "post-literatura” (LEMINSKI, 1977e: 6), que se caracterizaria pelo abandono da forma tanto da literatura como da antiliteratura e por uma multiplicação dos modos da escritura poética. Tanto 
o poeta como o pajé, portanto, buscam arrancar a tribo de seu "Eu" atual, para propiciar-lhe a possibilidade de um modo singular de dizer "Eu":

\author{
Contranarciso \\ em mim \\ eu vejo o outro \\ e outro \\ e outro \\ enfim dezenas \\ trens passando \\ vagóes cheios de gente \\ centenas \\ o outro \\ que há em mim \\ é você \\ você \\ e você \\ assim como \\ eu estou em você \\ eu estou nele \\ em nós \\ e só quando \\ estamos em nós \\ estamos em paz \\ mesmo que estejamos a sós \\ (LEMINSKI, 2013: 32)
}

No poema é possível ter uma ideia daquilo que Leminski imagina quando empresta dos poetas de haikai a ideia de "interpenetração dos seres": o Eu mergulha nos "vagóes cheios de gente" que o habitam, ao mesmo tempo em que se descobre habitante de outros. É possível imaginar essa "descoberta" como um processo de tradução, no qual o Eu que fala/traduz trai sua identidade (o conjunto de signos nos quais se reconhece) para fazer aparecer nele os outros que o constituem. A tradução é, portanto, o procedimento poético ascético por excelência, um trabalho sobre si por meio do qual o sujeito se abre para o outro e abandona a dicotomia nós-eu. Ao fim, há um retorno à solidão, mas uma solidão transformada, povoada por outros seres e outros tempos.

Considerações finais

A ascese leminskiana não é simplesmente um produto de seu "contexto histórico", reação a ele, mas um modo de temporalização que se coloca em conflito com outros. A historicidade desses modos de temporalização, 
portanto, deve ser pensada em suas relaçóes. Em diversos ensaios, Leminski aponta para uma necessidade de problematizar os tempos da civilização pós-industrial, que produziu, além da iminência da catástrofe ambiental e nuclear, uma imensa maquinaria de controle e capitalização do tempo. Esse aparato teria deixado sua marca inclusive em práticas literárias as mais diversas entre si, como a literatura social ou a poesia concreta. Cada uma a seu modo, elas teriam reificado em sua poética os modos de temporalização próprios ao ativismo capitalista, com sua teleologia desenvolvimentista. $\mathrm{O}$ asceta é, para Leminski, o personagem conceitual capaz de inventar outras formas de viver o tempo.

Quando Leminski evoca a imagem do "padre dos desertos", ele se refere à necessidade de, diante do "fim" dos "recursos naturais", de uma catástrofe ambiental iminente, inventar uma outra relação natureza/cultura. Não se trata, para o poeta, entretanto, de reduzir o uso que a cultura faz da natureza, o que significaria permanecer no interior da dinâmica daquela mesma economia, mas de reconfigurar o aparelho "econômico-mitológico" (LEMINSKI, 1977a: 5) para uma nova Era (que "não vai ser festival") na qual essa dicotomia (natureza e cultura) daria lugar a outras formas de relação entre sujeitos. O que está em questáo é uma certa ideia de subsistência (tal como a que Pierre Clastres já havia descrito em 1974), encarada como forma de vida, e não como incapacidade de produzir excedente. Contra os limites impostos pelo desenvolvimento e pelo ativismo (o fim dos recursos naturais que impediria a continuidade mesma desse desenvolvimento), importava "limitar o limite" (NODARI, 2014, p. 4), fazer desse limite algo outro, isto é, uma poética e uma prática do menos, uma vida com menos. Uma vida que precisaria ser criada a partir desse limite, dos restos, do lixo, mas também a partir de "agenciamentos sincréticos de alta intensidade" (DANOWSKI \& VIVEIROS DE CASTRO, 2014: 158), de uma "bricolagem tecnoprimitivista e da metamorfose político-metafísica” (DANOWSKI \& VIVEIROS DE CASTRO, 2014: 159). 
ANDERS, Gunter. Teses para a era atômica. Sopro: panfleto político-cultural. n. 87, pp. 2-10, 2013.

CÁMARA, Mario. Corpos pagãos: usos e figuraçôes na cultura brasileira (1960-1980). Belo Horizonte: Editora UFMG, 2014.

CUNHA, Manuela Carneiro da \& VIVEIROS DE CASTRO, Eduardo. Vingança e temporalidade: os Tupinamba. Journal de la Société des Américanistes, n. 71, 1985, pp. 191-208.

CLASTRES, Pierre. A sociedade contra o Estado. São Paulo: Cosac \&Naify, 2003.

DANOWSKI, Deborah \& VIVEIROS DE CASTRO, Eduardo. Há Mundo por vir? Ensaio sobre os medos e os fins. Florianópolis: Cultura e Barbárie: Instituto Socioambiental, 2014.

FOUCAULT, Michel. A hermenêutica do sujeito. São Paulo: Martins Fontes, 2016.

FOUCAULT, Michel. História da sexualidade 2: o uso dos prazeres. Rio de Janeiro: Graal, 1998.

LEITE, Elizabeth Rocha. Leminski: poeta da diferença. São Paulo: Edusp, 2012.

LEMINSKI, Paulo. Ascese e escassez. Diário do Paraná. Anexo. Curitiba, 30 jun. 1977a.

LEMINSKI, Paulo. Ensaios e anseios crípticos. Curitiba: Pólo Editorial do Paraná, $1997 \mathrm{~b}$.

LEMINSKI, Paulo. Ensaios e anseios crípticos. 2. ed. ampliada. São Paulo: Unicamp, 2012.

LEMINSKI, Paulo. Toda Poesia. São Paulo: Companhia das Letras, 2013, p. 32. Originalmente publicado em: VÁRIOS AUTORES. Sangra: cio. Curitiba, 1980.

LEMINSKI, Paulo. Rigor (Futebol Clube) x Invenção (Esporte e Regatas). Diário do Paraná. Anexo, Curitiba, 1. fev. 1977c.

LEMINSKI, Paulo. Eu quero viver de verdade, eu fico com o cinema americano. Em: LEMINSKI, Paulo. Memória de vida: Paulo poeta Leminski. Curitiba, 23 ago. 1989.

LEMINSKI, Paulo. Pajé. Diário do Paraná. Anexo. Curitiba, 7. jan. 1977d.

LEMINSKI, Paulo. Alegria, alegria: a post-literatura. Diário do Paraná. Anexo. Curitiba, 16 jul. 1977 e.

LEMINSKI, Paulo. X poetas e uma geração possível. Pólo Cultural. Curitiba, 1978. 
NODARI, Alexandre. Limitar o limite: modos de subsistência. Em: Os mil nomes de Gaia: do Antropoceno à Idade da Terra, 2014.

SUSSEKIND, Flora. Hagiografias. Em: GARRAMUÑO, Florencia; AGUILAR, Gonzalo; DI LEONE, Moisés (org.). Experiencia, cuerpo y subjetividades: literatura brasileña contemporánea. Buenos Aires: BVE, 2008.

VIVEIROS DE CASTRO, Eduardo. Desenvolvimento econômico e reenvolvimento cosmopolítico: da necessidade extensiva à suficiência intensiva. Sopro: panfleto político-cultural, n. 51, pp. 3-10, 2011.

VIVEIROS DE CASTRO, Eduardo. Metafisicas canibais. São Paulo: Cosac Naify/N-1, 2015.

Everton de Oliveira Moraes é Doutor em História pela Universidade Federal do Paraná e mestre em História Cultural pela Universidade Federal de Santa Catarina, pesquisando principalmente temáticas que dizem respeito ao problema do tempo e da historicidade nas artes e na literatura.

E-mail: moraes.everton@gmail.com 